E-JURNAL EKONOMI DAN BISNIS UNIVERSITAS UDAYANA
Available online at https://ojs.unud.ac.id/index.php/EEB/index
Vol. 10 No. 11, November 2021, pages: 991-1000
e-ISSN: 2337-3067

\title{
PENGARUH LITERASI KEUANGAN, KEPERCAYAAN, DAN KEAMANAN PEMBAYARAN TERHADAP KEPUTUSAN PEMBELIAN DI MARKETPLACE
}

\author{
Firda Nur Aini ${ }^{1}$ Susanti $^{2}$
}

\begin{tabular}{l}
\hline \multicolumn{1}{c}{ Article history: } \\
\hline Submitted: 3 Juni2021 \\
Revised: 23 Juni2021 \\
Accepted: 5 Juli2021 \\
\end{tabular}

Keywords:

Financial Literacy;

Trust;

Payment Security;

Marketplace;

\section{Kata Kunci:}

Literasi Keuangan;

Kepercayaan;

Keamanan Pembayaran;

Marketplace;

\section{Koresponding:}

Fakultas Ekonomika dan

Bisnis Universitas Negeri

Surabaya, Jawa Timur,

Indonesia

Email:firda.17080304036@mh

s.unesa.ac.id

\section{Abstract}

The main objective of this research is to determine the effect of financial literacy, trust, and payment securityon purchasing decisions in the marketplace. The approach used is quantitative and uses the causal associative method. The study population was students of Surabay a State UniversityAccounting Education and for sampling used saturated sampling technique, where all members of the population who havemade purch ases in the marketplace are used as samples. Data werecollected through tests and questionnaires which were then tested using multiple linear regression analysis techniques. The results showed thateach independent variable had a partial and significant effect on the dependent variable because the results t count $>$ t table, and the significance value showed the results below 0.05 . The variables offinancial literacy, trust, and payment security also simultaneously and significantly influence purchasing decisions in the marketplace with the results of F count (43.344)> F table (2.680) and a significance value of $0.00<0.05$. The result of the coefficient of determination $\left(R^{2}\right)$ shows thenumber 0.512 , which means that the influence offinancial literacy, trust, and payment security variables is $51.2 \%$ and the remaining $48.8 \%$ is influenced byother factors.

\begin{tabular}{|c|}
\hline Abstrak \\
\hline 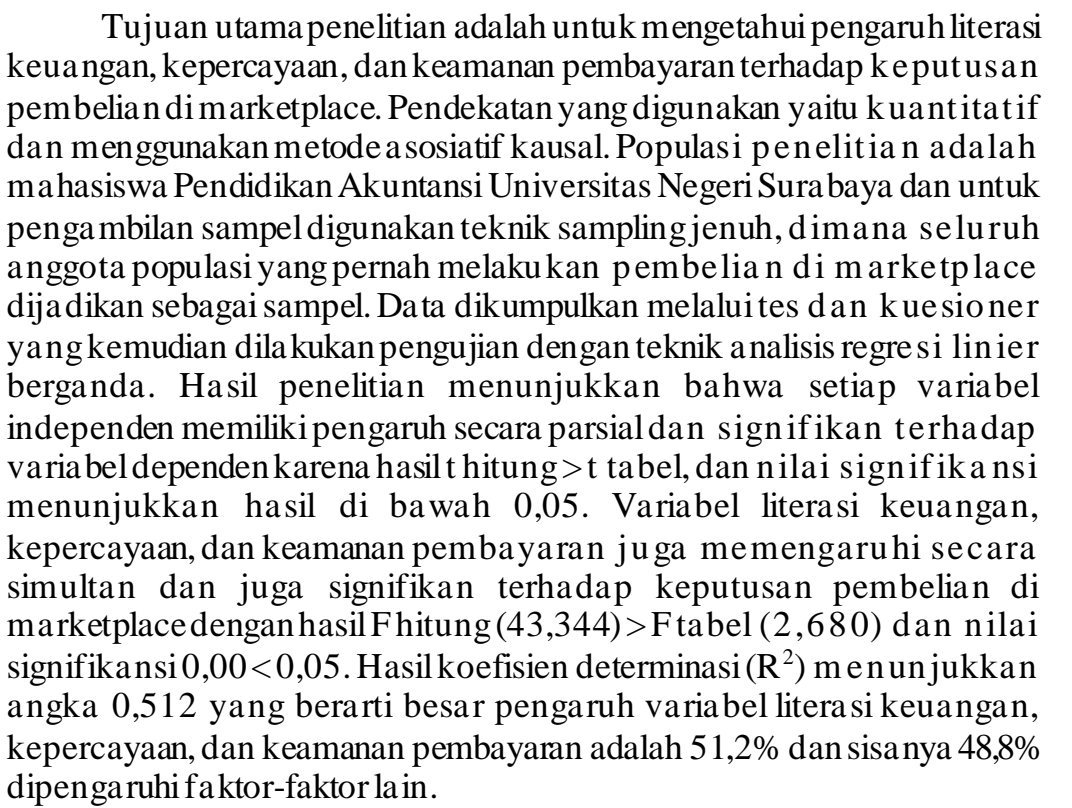 \\
\hline
\end{tabular}

Fakultas Ekonomika dan Bisnis Universitas Negeri Surabaya, Ja wa Timur, Indonesia ${ }^{2}$ 


\section{PENDAHULUAN}

Teknologi informasi yang terus mengalami perkembangan salah satunya adalah internet. Dalam bidang ekonomi, internet menjadi media dalam transaksi jual beli online. Pada masa pandemi covid19, jual beli secara online mengalami peningkatan yang pesat. Berdasarkan data yang telah dihitung oleh Badan Pusat Statistik (BPS) dalam (Pink, 2020), penjualan online selama pandemi April 2020 mengalami peningkatan sebesar $480 \%$ dari awal tahun. Hal tersebut menunjukkan bahwa masyarakat Indonesia tertarik pada transaksi jual beli secara online.

Tempat yang sering digunakan untuk transaksi jual beli online salah satunya adalah marketplace. Marketplace bertindak sebagai pihak ketiga yang menyediakan tempat bertemunya penjual dan pembeli secara online. Salah satu tujuan penjual memasarkan barang dagangannya di marketplace adalah untuk mencapai jangkauan pasar yang lebih luas (Jiang \& Liu, 2012). Begitupun pembeli tertarik belanja di marketplace karena dapat menemukan barang yang dibutuhkan secara mudah dan cepat (Al Farisi et al., 2020). Di Indonesia, terdapat beberapa marketplace yang cukup terkenal seperti Shopee, Tokopedia, Bukalapak, Lazada, Blibli, Zalora, dan masih banyak lagi.

Banyaknya marketplace di Indonesia mengakibatkan persaingan lebih ketat. Marketplace harus mampu meyakinkan konsumen dengan memberikan informasi yang tepat (Pudjihardjo \& Wijaya, 2015), karena hal tersebut menjadi salah satu pertimbangan sebelum memutuskan pembelian di marketplace. Keputusan pembelian merupakan sikap atau tindakan konsumen untuk memilih beberapa alternatif produk atau jasa yang akan digunakan (Tobing \& Bismala, 2015). Pada proses pengambilan keputusan, calon konsumen akan mempertimbangkan berbagai hal sebelum menggunakan produk atau jasa yang akan dipilih. Sebagian orang menganggap bahwa pembelian secara online memiliki resiko yang tinggi terutama dalam pembayaran dan pengiriman barang (Suresh, A.M. \& Shashikala, 2011).

Menurut (William \& Aripradono, 2020), faktor yang berpengaruh pada keputusan pembelian online di marketplace adalah adanya jaminan keamanan dan pilihan alternatif pembayaran yang disediakan. Sedangkan menurut (Mauludiyahwati, 2017), faktor yang memengaruhi keputusan pembelian online yaitu keamanan, kepercayaan, kualitas pelayanan yang diberikan, dan persepsi resiko konsumen. Selain faktor di atas, faktor yang cukup penting dalam keputusan pembelian yaitu literasi keuangan. Hal ini dikarenakan literasi keuangan merupakan dasar pengetahuan dalam pengambilan keputusan keuangan.

Pengetahuan tentang keuangan yang dimiliki seseorang dapat disebut sebagai literasi keuangan. Menurut (Ansong \& Gyensare, 2012), literasi keuangan merupakan pengetahuan dan keterampilan seseorang dan memungkinkan seseorang untuk mengambil keputusan yang benar dan efektif. Literasi keuangan dapat menghindarkan seseorang dari permasalahan keuangan (Silalahi, 2020) dan (Wijayanti et al., 2016), karena masalah keuangan tidak hanya timbul akibat dari pendapatan yang rendah, namun juga berdasarkan kemampuan seseorang dalam mengelola keuangan (Wahyuni et al., 2019).

Menurut (Nidar \& Bestari, 2012), literasi keuangan di masyarakat masih kurang sehingga mereka belum menyadari risikonya. (N. T. Herawati et al., 2018) mengatakan akibat adanya perkembangan teknologi di bidang keuangan, membuat seseorang sulit membedakan antara kebutuhan dan keinginan. Seseorang yang membeli barang sesuai keinginannya saja tanpa memikirkan kegunaannya hanya akan membuatnya berperilaku konsumtif. Untuk mengurangi perilaku konsumtif ini diperlukan pengetahuan keuangan (Khumairo \& Susanti, 2016) agar seseorang dapat mengelola keuangannya dan mengendalikan keinginan untuk berbelanja.

Seseorang dengan literasi keuangan tinggi akan melakukan pengelolaan keuangan yang baik (Laily, 2016). Mereka cenderung memikirkan kebutuhan apa yang diperlukan sebelum memutuskan

Pengaruh Literasi Keuangan, Kepercayaan Dan Keamanan Pembayaran Terhadap Keputusan Pembelian Di 
untuk berbelanja. Sebaliknya, seseorang dengan literasi keuangan rendah akan sulit mengendalikan diri untuk tidak berbelanja dan tidak memikirkan seberapa besar pengeluaran mereka. Oleh karena itu, manusia harus lebih bijak dalam memutuskan pembelian barang sesuai kebutuhan agar tidak terjadi pemborosan. Penelitian (Wahyuni et al., 2019) menunjukkan hasil terdapat pengaruh signifikan literasi keuangan terhadap perilaku konsumtif berbelanja online.

Faktor kedua yang mungkin berpengaruh pada keputusan pembelian di marketplace yaitu kepercayaan konsumen. Kepercayaan didefinisikan sebagai tingkat kepercayaan konsumen terhadap marketplace untuk melakukan transaksi dan menyerahkan identitas diri. Menurut (Baskara \& Hariyadi, 2014), kepercayaan menjadi kunci utama dalam transaksi jual beli online. Kepercayaan dapat menentukan sukses tidaknya transaksi yang dilakukan (Saraswati \& Rahyuda, 2020). Kepercayaan dianggap penting karena saat bertransaksi secara online, kondisi barang yang akan dibeli tidak dapat dilihat langsung oleh konsumen.

Sebelum memutuskan membeli produk di marketplace, konsumen akan mencari berbagai informasi mengenai marketplace. Mereka dapat menemukan informasi melalui penilaian atau review dari seseorang yang sebelumnya telah membeli pada situs marketplace tersebut. Kepercayaan pembeli juga dapat dipengaruhi oleh reputasi marketplace yang informasinya dapat diperoleh dari mulut ke mulut. Hal ini sejalan dengan yang dikemukakan (Effendi, 2016) dimana keputusan pembelian sangat ditentukan oleh keyakinan calon konsumen serta dari identifikasi berbagai informasi terkait produk ataupun jasa yang akan dibeli.

Hasil penelitian dari (Ilmiyah \& Krishernawan, 2020) menunjukkan hasil bahwa terdapat pengaruh yang positif dan signifikan kepercayaan pada keputusan pembelian konsumen di marketplace Shopee. Namun berdasarkan penelitian (Baskara \& Hariyadi, 2014), kepercayaan memengaruhi secara positif namun tidak signifikan pada keputusan pembelian konsumen. Hasil tersebut berlawanan dengan penelitian (Wardoyo \& Andini, 2017) yang menunjukkan hasil bahwa tidak adanya pengaruh antara kepercayaan terhadap keputusan pembelian konsumen secara online. Oleh sebab itu diperlukan penelitian yang lebih mengenai pengaruh kepercayaan pembeli terhadap keputusan pembelian di marketplace.

Selain kedua faktor di atas, konsumen juga mempertimbangkan faktor keamanan pembayaran. Keamanan pembayaran merupakan kemampuan marketplace melindungi identitas konsumen pada saat transaksi. Keamanan merupakan inti dari sebagian besar transaksi internet (Raman \& Annamalai, 2011). Faktor keamanan ini dianggap penting karena dapat menyangkut identitas pembeli serta keamanan dalam pembayaran. Sebelum memutuskan pembelian, calon pembeli mempertimbangkan sistem keamanan pembayaran dari marketplace agar data yang diberikan tidak akan disalahgunakan oleh pihak lain.

Adanya sistem pembayaran yang mudah dan aman dapat mendukung marketplace agar pembeli nyaman dalam bertransaksi. (Baskara \& Hariyadi, 2014) mengatakan bahwa tanpa adanya jaminan keamanan yang memadai dapat menyebabkan kekhawatiran tersendiri bagi konsumen, sehingga menghalangi mereka untuk melakukan pembelian. (William \& Aripradono, 2020) juga mengatakan bahwa kepercayaan masyarakat Indonesia pada sistem pembayaran digital terutama melalui perbankan masih rendah. Padahal sistem pembayaran melalui perbankan merupakan sistem pembayaran utama yang disediakan oleh marketplace.

Penelitian yang dilakukan (William \& Aripradono, 2020) menunjukkan hasil dimana jaminan keamanan atau yang disebut integritas online dan alternatif pembayaran yang beragam memiliki pengaruh signifikan pada keputusan pembelian secara online dengan hasil signifikansi 0,014. Namun berbeda dengan penelitian (Sukma, 2012) yang menunjukkan hasil security atau keamanan tidak berpengaruh signifikan.

Pengaruh Literasi Keuangan, Kepercayaan Dan Keamanan Pembayaran Terhadap Keputusan Pembelian Di 
Berdasarkan uraian di atas, terdapat kemungkinan bahwa (1) literasi keuangan berpengaruh pada keputusan pembelian di marketplace, (2) kepercayaan berpengaruh pada keputusan pembelian di marketplace, (3) keamanan pembayaran berpengaruh pada keputusan pembelian di marketplace, dan (4) literasi keuangan, kepercayaan, dan keamanan pembayaran berpengaruh secara simultan pada keputusan pembelian di marketplace.

\section{METODE PENELITIAN}

Pendekatan penelitian ini yaitu pendekatan kuantitatif. Penelitian yang dilakukan menggunakan metode asosiatif kausal karena bertujuan untuk mencari pengaruh atau hubungan sebab akibat. Terdapat dua macam variabel pada penelitian yaitu independen dan dependen, dimana variabel independennya yaitu literasi keuangan (X1), kepercayaan (X2), dan keamanan pembayaran (X3). Indikator variabel literasi keuangan menurut Chen \& Volpe dalam (N. S. Herawati \& Lutfi, 2015), yaitu pengetahuan seseorang tentang dasar keuangan, tabungan, asuransi, dan investasi. Indikator variabel kepercayaan menurut (Kim et al., 2003) dalam (Sukma, 2012), yaitu jaminan kepuasan, perhatian, dan keterusterangan yang diberikan marketplace kepada konsumen. Sedangkan indikator keamanan pembayaran menurut Raman \& Annamalai dalam (Mauludiyahwati, 2017), dapat dilihat dari kerahasiaan data dan jaminan keamanan yang diberikan marketplace.

Sedangkan variabel dependen penelitian yaitu keputusan pembelian di marketplace. Menurut (Siburian \& Ginting, 2013), indikator keputusan pembelian yaitu sesuai dengan kebutuhan, memiliki manfaat, keputusan yang tepat dalam membeli produk, serta pembelian ulang. Penelitian ini menggunakan populasi mahasiswa program studi Pendidikan Akuntansi Universitas Negeri Surabaya. Roscoe dalam (Sugiyono, 2016) mengatakan bahwa dalam penelitian, ukuran sampel yang digunakan yaitu minimal 30 sampel. Pada penelitian ini, sampel diambil menggunakan teknik sampling jenuh dimana seluruh anggota populasi yang pernah melakukan transaksi pembelian di marketplace digunakan sebagai sampel. Berdasarkan hasil pengisian kuesioner terdapat 122 responden yang pernah bertransaksi di marketplace, sehingga responden tersebut yang digunakan sebagai sampel penelitian.

Data penelitian dikumpulkan melalui tes dan kuesioner yang dikirimkan langsung melalui google formulir. Tes digunakan untuk mengukur variabel literasi keuangan yang diukur menggunakan skala guttman. Sedangkan kuesioner digunakan untuk mengukur variabel kepercayaan, keamanan pembayaran, dan keputusan pembelian di marketplace. Kuesioner ini menggunakan skala likert yang di dalamnya terdapat alternatif jawaban yang akan dipilih oleh responden. Data penelitian dianalisis menggunakan teknik analisis regresi linier berganda yang berfungsi untuk pengujian pengaruh dari beberapa variabel independen pada satu variabel dependen, dan analisis data menggunakan bantuan SPSS versi 22. Berikut persamaan analisis regresi linier berganda yang digunakan.

$$
\mathbf{Y}=\alpha+\beta 1 \times 1+\beta 2 \times 2+\beta n X n+e
$$

Keterangan :

$\begin{array}{ll}\mathrm{X} 1 & \text { : Literasi Keuangan } \\ \mathrm{X} 2 & \text { : Kepercayaan } \\ \mathrm{X} 3 & \text { : Keamanan Pembayaran } \\ \mathrm{Y} & \text { : Keputusan Pembelian di Marketplace }\end{array}$

Pengaruh Literasi Keuangan, Kepercayaan Dan Keamanan Pembayaran Terhadap Keputusan Pembelian Di 


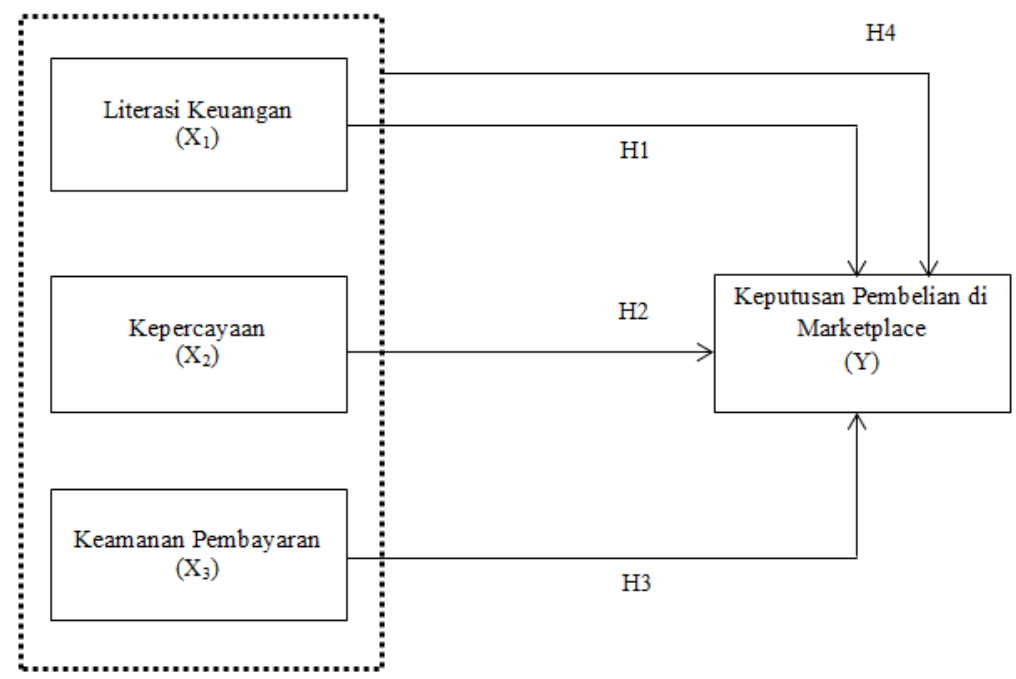

Sumber: Data Diolah Penulis, 2021

\section{Gambar 1. \\ Kerangka Konsep Penelitian}

\section{HASIL DAN PEMBAHASAN}

Dalam penelitian ini, data yang dibutuhkan harus memiliki distribusi yang normal, sehingga dilakukan uji normalitas data terlebih dahulu. Uji dilakukan dengan Kolmogrov-Smirnov $(K-S)$ dengan hasil berikut.

Tabel 1.

Hasil Uji Normalitas Data

\begin{tabular}{lc}
\hline & Unstandardized Residual \\
\hline $\mathrm{N}$ & 122 \\
Test Statistic &, 079 \\
Asymp. Sig. (2-tailed) &, $062^{\mathrm{c}}$ \\
\hline
\end{tabular}

Sumber: Data Pengolahan SPSS, 2021

Berdasarkan Tabel 1 menunjukkan hasil signifikansi 0,062 yang berarti data untuk penelitian memiliki distribusi yang normal karena nilai signifikansinya di atas 0,05 . Adapun uji linieritas yang digunakan untuk mengetahui bagaimana hubungan linier antar variabel. Berikut hasil uji yang telah dilakukan dengan SPSS 22.

Pengaruh Literasi Keuangan, Kepercayaan Dan Keamanan Pembayaran Terhadap Keputusan Pembelian Di 
Tabel 2.

Hasil Uji Linieritas

\begin{tabular}{|c|c|c|c|c|c|c|c|}
\hline & & & $\begin{array}{l}\text { Sum of } \\
\text { Squares }\end{array}$ & Df & $\begin{array}{l}\text { Mean } \\
\text { Square }\end{array}$ & $\mathrm{F}$ & Sig. \\
\hline \multirow{5}{*}{$\begin{array}{l}\text { Unstandardized } \\
\text { Residual * } \\
\text { Unstandardized } \\
\text { Predicted } \\
\text { Value }\end{array}$} & \multirow{3}{*}{$\begin{array}{l}\text { Between } \\
\text { Groups }\end{array}$} & (Combined) & 914,147 & 93 & 9,830 & 2,663 & ,002 \\
\hline & & Linearity &, 000 & 1 &, 000 &, 000 & 1,000 \\
\hline & & $\begin{array}{l}\text { Deviation } \\
\text { from } \\
\text { Linearity }\end{array}$ & 914,147 & 92 & 9,936 & 2,692 &, 002 \\
\hline & \multicolumn{2}{|c|}{ Within Groups } & 103,333 & 28 & 3,690 & & \\
\hline & \multicolumn{2}{|l|}{ Total } & 1017,480 & 121 & & & \\
\hline
\end{tabular}

Sumber: Data Pengolahan SPSS, 2021

Berdasarkan tabel 2 nilai signifikansi sebesar 1,00 >0,05, sehingga disimpulkan bahwa variabel independen dan variabel dependen penelitian mempunyai hubungan yang linier. Kemudian, sebelum melakukan analisis regresi berganda juga perlu dilakukan uji multikolinieritas. Hasil uji dengan SPSS 22 disajikan dalam tabel berikut.

Tabel 3.

Hasil Uji Multikolinieritas

\begin{tabular}{lcc}
\hline \multirow{2}{*}{ Model } & \multicolumn{2}{c}{ Collinea rity Statistics } \\
\cline { 2 - 3 } & Tolerance & VIF \\
\hline (Constant) & & 1,056 \\
LITERASI KEUANGAN &, 947 & 1,755 \\
KEPERCAYAAN &, 570 & 1,784 \\
KEAMANANPEMBAYARAN &, 560 & \\
\hline
\end{tabular}

Sumber: Data Pengolahan SPSS, 2021

Suatu data dapat disimpulkan tidak terjadi multikolinieritas jika hasil Tolerance $>0,10$ dan hasil VIF $<10$. Berdasarkan tabel 3 menunjukkan hasil tidak adanya multikolinieritas. Selanjutnya dilakukan uji heteroskedastisitas menggunakan Uji Park, yang hasilnya tertera pada tabel berikut.

Tabel 4.

\section{Uji Heteroskedastisitas}

\begin{tabular}{lc}
\hline Model & Sig. \\
\hline (Constant) &, 070 \\
LITERASI KEUANGAN &, 139 \\
KEPERCAYAAN &, 717 \\
KEAMANAN PEMBAYARAN &, 091 \\
\hline
\end{tabular}

Sumber: Data Pengolahan SPSS, 2021

PengaruhLiterasi Keuangan, Kepercayaan Dan Keamanan Pembayaran Terhadap Keputusan Pembelian Di 
Berdasarkan Uji Park pada tabel 4, data dapat dikatakan tidak terjadi heteroskedastisitas jika hasil signifikansi lebih dari 0,05 , sehingga data dinyatakan tidak terjadi heteroskedastisitas. Hasil analisis regresi linier berganda yang dilakukan dengan SPSS 22 menunjukkan hasil berikut.

Tabel 5.

Analisis Regresi Linier Berganda

\begin{tabular}{|c|c|c|c|c|c|}
\hline \multirow{2}{*}{ Model } & \multicolumn{2}{|c|}{$\begin{array}{l}\text { Unstandardized } \\
\text { Coefficients }\end{array}$} & \multirow{2}{*}{$\begin{array}{c}\begin{array}{c}\text { Standardized } \\
\text { Coefficients }\end{array} \\
\text { Beta }\end{array}$} & \multirow[t]{2}{*}{$\mathrm{t}$} & \multirow[t]{2}{*}{ Sig. } \\
\hline & $\mathrm{B}$ & Std.Error & & & \\
\hline (Constant) & 9,295 & 2,851 & & 3,260 & ,001 \\
\hline LITERASI KEUANGAN & ,229 &, 108 & ,138 & 2,118 & ,036 \\
\hline KEPERCAYAAN &, 765 &, 137 & ,468 & 5,568 & 000 \\
\hline $\begin{array}{l}\text { KEAMANAN } \\
\text { PEMBAYARAN }\end{array}$ &, 543 &, 133 &, 345 & 4,072 &, 000 \\
\hline
\end{tabular}

Sumber: Data Pengolahan SPSS, 2021

Adapun persamaan yang diperoleh yaitu:

$$
\mathrm{Y}=9,295+0,229 \mathrm{X}_{1}+0,765 \mathrm{X}_{2}+0,543 \mathrm{X}_{3}
$$

Berdasarkan Tabel 5, nilai konstanta sebesar 9,295 yang artinya jika tidak terjadi perubahan variabel literasi keuangan, kepercayaan, dan keamanan pembayaran maka keputusan pembelian di marketplace ada sebesar 9,295 satuan. Sedangkan nilai koefisien regresi literasi keuangan adalah sebesar 0,229 yang artinya jika variabel literasi keuangan (X1) meningkat 1\% dengan asumsi bahwa variabel kepercayaan (X2), keamanan pembayaran (X3), dan konstanta 0 (nol), maka keputusan pembelian di marketplace juga meningkat sebesar 0,229.

Begitu juga pada variabel kepercayaan yang menunjukkan hasil koefisien regresi sebesar 0,765 sehingga saat variabel kepercayaan meningkat sebesar $1 \%$ maka berpengaruh pada peningkatan keputusan pembelian di marketplace sebesar 0,765. Dan koefisien regresi keamanan pembayaran menunjukkan nilai sebesar 0,543 sehingga setiap kenaikan variabel keamanan pembayaran sebesar $1 \%$ juga berpengaruh pada peningkatan keputusan pembelian di marketplace sebesar 0,543. Uji t yang berguna untuk pengujian pengaruh setiap variabel independen terhadap variabel dependen disajikan dalam tabel berikut.

Tabel 6.

Hasil Uji t

\begin{tabular}{lccc}
\hline Model & t hitung & t table & \multirow{2}{*}{ Sig. } \\
\hline LITERASI KEUANGAN & 2,118 & 1,98 &, 036 \\
KEPERCAYAAN & 5,568 & 1,98 &, 000 \\
KEAMANAN PEMBAYARAN & 4,072 & 1,98 &, 000 \\
\hline
\end{tabular}

Sumber: Data Pengolahan SPSS, 2021

Berdasarkan Tabel 6, diketahui besar t hitung pada variabel literasi keuangan lebih dari $\mathrm{t}$ tabel. Nilai signifikansi yang diperoleh juga di bawah 0,05 sehingga H1 diterima dan diambil kesimpulan bahwa literasi keuangan berpengaruh pada keputusan pembelian di marketplace. Variabel

\footnotetext{
Pengaruh Literasi Keuangan, Kepercayaan Dan Keamanan Pembayaran Terhadap Keputusan Pembelian Di 
literasi keuangan berpengaruh secara positif, yang dapat diartikan jika literasi keuangan konsumen meningkat, maka keputusan pembelian di marketplace juga mengalami peningkatan. Konsumen dengan literasi keuangan tinggi dapat mengambil keputusan keuangan yang lebih tepat dan dapat menentukan prioritas kebutuhan mereka, sehingga saat memutuskan membeli barang di marketplace mereka hanya membeli barang yang bermanfaat dan sesuai kebutuhan. Konsumen dengan karakteristik tersebut dapat menghindari masalah keuangan dengan menekan pola hidup konsumtif. Hasil penelitian tersebut sejalan dengan hasil penelitian yang dilakukan oleh (Wahyuni et al., 2019).

Variabel kepercayaan memperoleh nilai thitung yang lebih besar dari t tabel dan perolehan nilai signifikansi $0,00<0,05$ sehingga $\mathrm{H} 2$ diterima. Variabel kepercayaan dinyatakan memiliki pengaruh positif pada keputusan pembelian di marketplace, yang artinya semakin meningkat kepercayaan konsumen maka meningkat pula keputusan konsumen untuk membeli di marketplace. Jika konsumen percaya bahwa marketplace telah memberikan informasi secara lengkap dan dapat memberikan kepuasan dalam transaksi, maka konsumen tidak akan ragu untuk menggunakan jasa marketplace dalam memenuhi kebutuhannya. Kepercayaan konsumen pada marketplace dapat diperkuat dengan informasi yang mereka peroleh dari pihak keluarga, teman, ataupun orang lain yang telah memiliki pengalaman dalam hal pembelian melalui marketplace. Hasil penelitian yang diperoleh sejalan dengan hasil yang diperoleh dalam penelitian (Ilmiyah \& Krishernawan, 2020).

Nilai t hitung $(4,072)$ pada variabel keamanan pembayaran lebih besar dari t tabel $(1,980)$ dan perolehan nilai signifikansi $0,00<0,05$ sehingga $\mathrm{H} 3$ dapat diterima. Keamanan pembayaran menunjukkan hasil positif, sehingga ketika keamanan pembayaran mengalami peningkatan maka keputusan pembelian di marketplace juga meningkat. Jika marketplace memberikan jaminan keamanan dalam hal pembayaran selama transaksi, maka konsumen akan tertarik untuk melakukan pembelian di marketplace. Konsumen tidak akan takut untuk memberikan identitas selama transaksi jika marketplace dapat menjamin kerahasiaan data konsumen. Alternatif pembayaran yang beragam juga berpengaruh bagi konsumen, seperti pembayaran melalui minimarket, Cash On Delivery (COD), dan perbankan. Konsumen akan lebih nyaman jika mereka dapat memilih sistem pembayaran yang dirasa lebih aman. Hasil yang diperoleh sejalan dengan penelitian (William \& Aripradono, 2020) yang menunjukkan hasil dimana jaminan keamanan atau integritas online, serta alternatif pembayaran yang beragam berpengaruh signifikan.

Uji F dalam penelitian ini, berguna untuk pengujian secara simultan antara seluruh variabel independen pada variabel dependen. Hasil dari uji F menggunakan SPSS 22 tertera di bawah ini.

Tabel 7.

Hasil Uji F

\begin{tabular}{llccccc}
\hline \multirow{2}{*}{ Model } & Sum of Squares & Df & Mean Square & F & Sig. \\
\hline \multirow{2}{*}{1} & Regression & 1121,241 & 3 & 373,747 & 43,344 &, $000^{\mathrm{b}}$ \\
& Residual & 1017,480 & 118 & 8,623 & & \\
& Total & 2138,721 & 121 & & & \\
\hline
\end{tabular}

Sumber: Data Pengolahan SPSS, 2021

Berdasarkan tabel 7, diketahui bahwa hasil F hitung $(43,344)>\mathrm{F}$ tabel $(2,680)$ dan hasil signifikansi $0,00<0,05$ sehingga $\mathrm{H} 4$ dapat diterima. Hal ini berarti variabel literasi keuangan, kepercayaan, dan keamanan pembayaran secara simultan memengaruhi keputusan pembelian di marketplace. Hasil koefisien determinasi $\left(\mathrm{R}^{2}\right)$ pada penelitian ini berguna untuk mengetahui besarnya

Pengaruh Literasi Keuangan, Kepercayaan Dan Keamanan Pembayaran Terhadap Keputusan Pembelian Di 
pengaruh ketiga variabel independen terhadap variabel dependen. Hasil yang diperoleh adalah sebagai berikut.

Tabel 8.

Hasil Koefisien Determinasi $\left(\mathbf{R}^{2}\right)$

\begin{tabular}{ccccc}
\hline Model & $\mathrm{R}$ & R Square & $\begin{array}{c}\text { Adjusted R } \\
\text { Square }\end{array}$ & $\begin{array}{c}\text { Std.Error of } \\
\text { the Estimate }\end{array}$ \\
\hline 1 &, $724^{\mathrm{a}}$ &, 524 &, 512 & 2,936 \\
\hline Sumber: Data Pengolahan SPSS, 2021 & &
\end{tabular}

Berdasarkan tabel 8, hasil Adjusted R Square menunjukkan angka 0,512 yang artinya besar pengaruh variabel literasi keuangan, kepercayaan, dan keamanan pembayaran terhadap keputusan pembelian di marketplace adalah 51,2\%. Hal itu berarti faktor lain juga berpengaruh pada keputusan pembelian di marketplace dengan nilai sebesar $48,8 \%$.

\section{SIMPULAN DAN SARAN}

Berdasarkan penelitian, dapat diambil kesimpulan bahwa variabel literasi keuangan, kepercayaan, dan keamanan pembayaran masing-masing memengaruhi secara positif dan juga signifikan pada variabel keputusan pembelian di marketplace. Artinya, jika literasi keuangan dan kepercayaan yang ada dalam diri konsumen meningkat, juga akan berdampak pada meningkatnya keputusan pembelian konsumen di marketplace. Keamanan pembayaran pada marketplace yang dirasa aman bagi konsumen juga meningkatkan keputusan pembelian di marketplace tersebut. Ketiga variabel independen yaitu literasi keuangan, kepercayaan, dan keamanan pembayaran juga memengaruhi secara simultan dan signifikan pada variabel keputusan pembelian di marketplace. Hasil penelitian yang diperoleh dapat memperkaya konsep yang telah dikemukakan para ahli serta dapat memperkuat hasil penelitian terdahulu.

Saran yang dapat diberikan bagi marketplace yaitu adanya peningkatan pelayanan terhadap konsumen serta pemberian informasi yang lebih lengkap agar konsumen dapat lebih mempercayai transaksi melalui marketplace. Peningkatan keamanan pembayaran juga perlu dilakukan dengan menjaga informasi pribadi konsumen serta keamanan akun dan saldo yang ada pada aplikasi marketplace. Bagi peneliti selanjutnya diharapkan untuk meneliti lebih lanjut terutama pada variabel literasi keuangan, dikarenakan hasil menunjukkan bahwa variabel tersebut memiliki pengaruh yang lebih kecil dibanding dengan variabel lain. Penelitian yang dilakukan juga terbatas pada lingkup yang kecil, sehingga diharapkan adanya penelitian pada lingkup yang lebih luas serta meneliti faktor lain yang memiliki kemungkinan berpengaruh pada keputusan pembelian konsumen di marketplace.

\section{REFERENSI}

Al Farisi, S., Saroh, S., \& Hardati, R. N. (2020). Analisis Faktor-Faktor Yang Mempenga ruhi Minat Beli Konsumen Pada E-CommerceLazada (Studi Pa da Mahasiswa Universitas I slam Malang Pengguna Marketplace Lazada). Jiagabi, 9(2), 377-385.

Ansong, A., \& Gyensa re, M. A. (2012). Determinants of University Working-Students' Financial Literacy at the University of Cape Coast, Ghana. International Journal of Business and Management, 7(9). 126-133 https://doi.org/10.5539/ijbm.v7n9p126

Baskara, I.P., \& Hariy adi, G. T. (2014). Ana lisis Pengaruh Kepercayaan, Kea manan, Kualitas Pela yanan, dan Persepsi Akan Risiko Terhadap Keputusan Pembelian MelaluiSitus Jejaring Sosial. Jurnal Ekonomi Dan Kewirausahaan, 15(2). 1-12. http://eprints.dinus.ac.id/id/eprint/8814

Pengaruh Literasi Keuangan, Kepercayaan Dan Keamanan Pembayaran Terhadap Keputusan Pembelian Di 
Effendi, U.(2016). Psikologi Konsumen. PT RajaGrafindo Persada.

Herawati, N. S., \& Lutfi. (2015). Pengaruh Literasi Keuangan dan Faktor Demografi Terhadap Perilaku Konsumtif Mahasiswa Bisnis di Sura baya. Perbanas Institutional Repository.

Hera wati, N. T., Candiasa, I. M., Ya dnyana, I. K., \& Suharsono, N. (2018). Pengaruh Ku alita s Pembelajaran Keuangan dan Literasi Keuangan Terhadap Financial Self Efficacy Mahasis wa Akuntansi. JPEKA: Jurnal Pendidikan Ekonomi, Manajemen Dan Keuangan, 2(2), 115-128. https://doi.org/10.26740/jpeka.v2n2.p115-128

Ilmiyah, K., \& Krishernawan, I. (2020). Pengaruh Ulasan Produk, Kemudahan, Kepercayaan, dan Harga Terhadap Keputusan Pembelian Pada Marketplace Shopee di Mojokerto. Maker: Jurnal Manajemen, 6(1),31-42. https://doi.org/10.37403/mjm.v6i1.143

Jiang, Y., \& Liu, Y. (2012). Optimization of Online Promotion: A Profit-Maximizing ModelIntegrating Price Discount and Product Recommendation. International Journal of Information Technology and Decision Making, 11(5), 961-982.https://doi.org/10.1142/S0219622012500289

Khuma iro, N. U., \& Susanti. (2016). Studi Kompara si Litera si Keuangan Berda sarkan Faktor Demografi Mahasiswa Fakultas Ekonomi Universitas Negeri Surabaya Angkatan 2013. Jurnal Pendidikan Akuntansi(JPAK), 4(2).1-14.

Kim, D. J., Ferrin, D. L., \& Rao, R. (2003). International T Ransfer P Ricing and E Lectronic C Ommerce. 286290.

Laily, N. (2016). Pengaruh Literasi Keuangan Terhadap Perilaku Mahasiswa dalam Mengelola Keuangan. Journal of Accounting and Business Education, 1(4). 1-10. https://doi.org/10.26675/jabe.v1i4.6042

Ma uludiyahwati, S. (2017). Pengaruh Kepercayaan, Keamanan, Kualitas Pelayanan dan Persepsi RISIKO Meng gunakan e-Commerce Terhadap Keputusan Pembelian Online. Universitas Negeri Yogyakarta.

Nidar, S. R., \& Bestari, S. (2012). Personal Fina ncial Literacy Among University Students (Case Study at Padjadjaran University Students, Bandung, Indonesia). World Journal of Social Sciences, 2(4), $162-$ 171.

Pink, B. (2020). BPS Catat Penjualan Online Melonjak Tajam Selama Pandemi Corona. https://nasional.kontan.co.id/news/bps-catat-penjualan-online-melonjak-tajam-selama pandemi-corona

Pudjihardjo, M.C., \& Wijaya, H. (2015). Ana lisa Pengaruh Kepercayaan, Kemudahan, Kualitas Informasi, d a n Tampilan Produk Terhadap Keputusan Pembelian Melalui Pemasaran di Media Sosial (Studi Pa da Pengguna Media Sosial di Sha pewarve). Jurnal Hospitality Dan Manajemen Jasa, 3(2), 364-379.

Raman, A., \& Annamalai, V. (2011). Web Services and e-Shopping Decisions: A Study on Malaysian eConsumer. IJCA Special Issue on "Wireless Information Networks \& Business Information System” WINBIS, 54-60.

Saraswati, I. G. A. A. P., \& Rahyuda, I. K. (2020). Pengaruh PerceivedEase of Use, Perceived Usef uln ess d an Trust Terhadap RepurchaseIntention. E-JURNAL EKONOMI DAN BISNIS UNIVERSITAS UDAYANA, 10(02), 61-72. http://repository.uph.edu/6760/

Siburian, T.P., \& Ginting, L. (2013). Analisis Pengaruh Kualitas Pelayanan Kon sumen Pada Warung Ucok Durian Iskandar Muda Medan Terhadap Keputusan Pembelian. Media Informasi Manajemen, 53(9), 1689-1699.

Sila lahi, R. Y. B. (2020). Pengaruh Literasi Keuangan dan Gaya Hidup Terhadap Perila ku Konsumtif Berbelanja Online. Khazanah Ilmu Berazam, 3(1), 191-200. http://repository.umsu.ac.id/handle/123456789/5190

Sugiyono. (2016). Metode Penelitian Kuantitatif, Kualitatif, dan R\&D. Alfabeta.

Sukma, A. A. (2012). Analisis Faktor-Faktor yang Mempengaruhi Keputusan Pembelian melalui Social Networking Website. Jurnal Ekonomi Manajemen, 1(1), 1-11.

Suresh, A.M. \& Sha shikala, R. (2011). Identifying Factors of Consumer Perceived Risk toward Online Shopping in India.IPEDR, 12(2),336-341.http://www.ipedr.com/vol12/61-C137.pdf

Tobing, R.P., \& Bismala, L. (2015). Pengaruh Citra Merek dan Periklanan Terhadap Keputusan Pembelian Polis Asuransi. JurnalAkuntansi Dan Bisnis, 1(2), 73-82.

Wahyuni, R., Irfa ni, H., Sya hrina, I. A., \& Mariana, R. (2019). Pengaruh GayaHidup dan Literasi Ke u angan Terhadap Perilaku Konsumtif Berbelanja Online Pada Ibu Rumah Tangga di Kecamatan Lubuk Begalung Kota Padang. Jurnal Benefita, 4(3), 548-558. https://doi.org/10.22216/jbe.v4i3.4194

Wardoyo, W., \& Andini, I. (2017). Faktor-Faktor Yang Berpen garuh Terhadap Keputusan Pe mbelia n Secara Online Pada Mahasiswa Universitas Gunadarma. Jurnal Manajemen Dayasaing, 19(1), 1-12. https://doi.org/10.23917/dayasaing.v 19i1.5101

Wijayanti, Agustin, G., \& Rahmawati, F. (2016). Pengaruh Jenis Kelamin, IPK, dan Semester TerhadapLitera si Keuangan Mahasiswa Prodi S1 Ekonomi Pembangunan Universitas Negeri Malang. Jurnal Pendidikan Ekonomi,09(1), 88-98. https://dx.doi.org/10.17977/UM014v09i12016p088

PengaruhLiterasi Keuangan, Kepercayaan Dan Keamanan Pembayaran Terhadap Keputusan Pembelian Di 